Лемешева Жанна Сергеевна

кандидат экономических наук,

доцент кафедры экономики таможенного дела

Российской таможенной академии

\section{СОВЕРШЕНСТВОВАНИЕ МЕТОДИЧЕСКИХ ПОДХОДОВ, ПРИМЕНЯЕМЫХ В МАРКЕТИНГОВОМ ЦЕНООБРАЗОВАНИИ}

\section{Аннотация:}

В статье представлены результаты сопоставления способов анализа ценовой политики предприятия, которые заключаются в том, что в настоящее время не существует единого подхода к анализу ценовой политики на предприятии. Рассмотрены и описаны подходы разных авторов, занимавшихся вопросами ценообразования и разработки ценовой политики и стратегии предприятия. Недостаток этих методик и подходов состоит том, что в них не предложена последовательность проведения анализа ценовой политики с учетом всех факторов и элементов, недостаточно подробно рассмотрен вопрос адаптации ценовой политики к меняющимся условиям внешней среды. Автором представлены основные элементы и этапы разработки ценовой политики, а также показана такая методика анализа политики цен, которая позволяет вносить в нее определенные изменения и адаптировать ценовую политику для компаний различных сфер деятельности, что в конечном счете дает возможность фирме успешно функционировать на рынке.

\section{Ключевые слова:}

цена, ценовая политика, методика анализа ценовой политики, ценообразование, ценовая стратегия, ценовое поведение.

\section{Lemesheva Zhanna Sergeevna}

PhD in Economics, Assistant Professor, Customs Economy Department, Russian Customs Academy

\section{THE IMPROVEMENT OF METHODOLOGICAL APPROACHES IN MARKETING PRICING}

This article compares the different ways to analyze the pricing policy of the enterprise, which lie in the fact that currently there is no unified approach to the analysis of price policy for the company. The paper describes and discusses the approaches of different authors that dealt with pricing and the development of pricing policy and strategies in the enterprise. The disadvantage of these methods and approaches is that they are not a sequence analysis of the price policy taking all factors and elements into account. Besides, the adaptation of pricing policy to the changing external environment is insufficiently studied. The article presents the main elements and stages in the development of pricing policy. The author shows such a method of analyzing the price policy that allows one to change and adapt it for various companies. As a result, it gives the company an opportunity to operate successfully on the market.

Keywords: price, pricing policy, methods of price policy analysis, pricing, pricing strategy, price behavior.

Цена является одним из наиболее важных инструментов и критериев в принятии покупателем окончательного решения. На сегодняшний момент все большую роль начинают приобретать неценовые факторы конкуренции, но тем не менее цена сохраняет свои позиции и продолжает оказывать существенное влияние на рыночную долю фирмы, ее финансовые результаты [1].

Ценовая политика большинства компаний часто недостаточно эффективна ввиду того, что фрирмы допускают следующие распространенные ошибки: применяют политику ценообразования, ориентированную на издержки; цены не приспособлены к изменению рыночной конъюнктуры, цена применяется без взаимосвязи с другими элементами комплекса маркетинга-микс; цены не дифференцированы по различным сегментам рынка. В связи с этим данные ошибки могут привести к потере конкурентоспособности и занимаемой рыночной ниши, к ухудшению фринансового положения предприятия, а в ряде случаев и к существенным убыткам [2].

Актуальность исследования обусловлена важностью ценовой политики в деятельности предприятия, поскольку одним из самых эффективных и выгодных методов увеличения прибыли является совершенствование механизма ценообразования.

Каждый предприниматель должен овладеть не только теоретическими основами ценообразования, но и умением осуществлять всесторонний контроль над правильностью формирования цен на всех этапах, что в свою очередь позволит повысить фринансовую устойчивость, конкурентоспособность предприятия и обеспечить долгосрочную перспективу развития [3].

Анализ ценовой политики позволяет получить объективное и полное представление о достигнутом уровне, динамике и темпах развития предприятия, наличии неиспользованных резервов и прогнозировать его развитие в перспективе.

В настоящее время не существует единого подхода к анализу ценовой политики предприятия. В работах, посвященных данной тематике, можно увидеть, как каждый автор описывает 
свой вариант исследования. Например, А.И. Ковалев и В.В. Войленко предлагают проводить анализ ценовой политики в следующей последовательности: анализ уровня цены товара, цен конкурентов, структуры цены продукции, установление цены продукции.

В методике Г.В. Савицкой большое значение уделяется фракторному анализу уровня среднереализационных цен. Среднереализационная цена рассчитывается путем деления выручки от реализации соответствующего изделия на объем его продаж за отчетный период [4].

Согласно методике Н.В. Колчиной, чтобы оценить влияние цен на хозяйственные и фринансовые результаты деятельности фирмы, необходимо определить, какое влияние оказывают цены на прибыль от продажи. При этом следует провести анализ изменений в доходах, получаемых предприятием, возникающих в результате экономии от снижения себестоимости продукции и изменения себестоимости в результате структурных сдвигов в составе продукции. Таким образом, методика, предлагаемая Н.В. Колчиной, подразумевает анализ влияния на финансовые и хозяйственные результаты деятельности предприятия следующих факторов: изменение цен на материалы, тарифы и услуги.

Методика Н.А. Лупей и Г.А. Гориной предполагает анализ влияния не только цен, но и ценовой политики финансовых результатов деятельности коммерческого предприятия, а также влияние налога и действующей налоговой системы на основные финансово-хозяйственные показатели деятельности предприятия. Данная методика включает в себя расчет уровня торговой надбавки, который определяется в зависимости от выбора предприятием ценовой политики и ценовой стратегии. Также в методике рассматривается влияние издержек обращения на формирование цен. Кроме того, авторы данного метода предлагают проводить расчет точки безубыточности [5].

Согласно методике Е.А. Романовой, под ценовой политикой следует понимать модель принятия решений или экономический механизм поведения предприятия на различных типах рынков. Использование данной модели позволит предприятию достичь поставленных целей и получить прибыль.

Процесс разработки ценовой политики предприятия включает в себя следующие этапы (рис. 1):

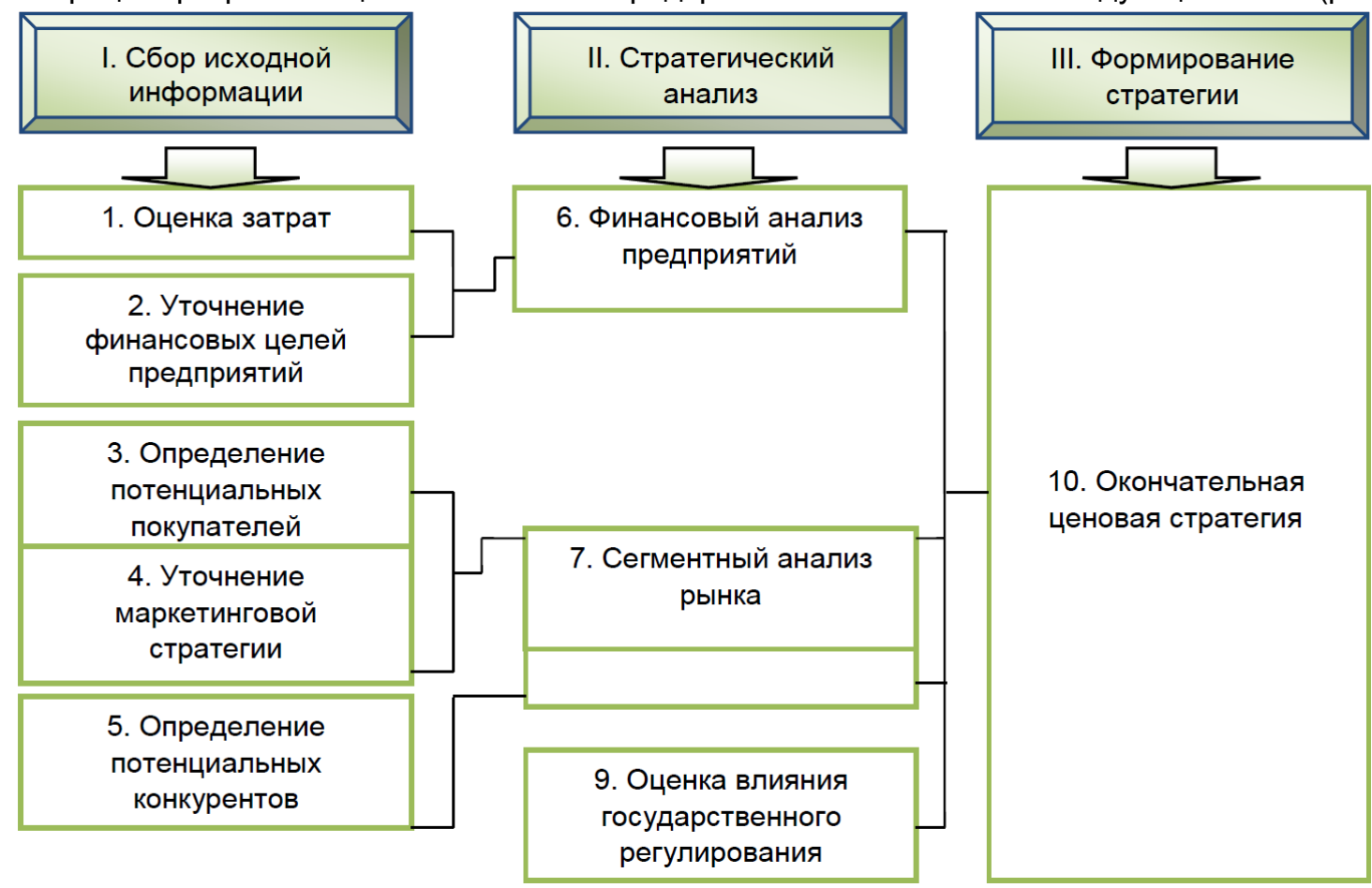

Рисунок 1 - Основные этапы и элементы разработки ценовой политики и ценовой стратегии на предприятии

Из приведенного выше рисунка следует, что конечным результатом разработки ценовой политики является формирование окончательной ценовой стратегии, которая в свою очередь является неотъемлемой частью общей стратегии развития предприятия [6].

Существует достаточно много отечественных и зарубежных источников, в которых описываются элементы ценовой политики и ценовой стратегии предприятия. Так, В.М. Тарасевич и И.И. Полещук достаточно полно описали различные методы ценообразования, которые применяются на предприятиях, функционирующих в различных сферах деятельности. Ф. Котлер в своих трудах подробно охарактеризовал модели ценового поведения на различных типах рынка. 
В.В. Герасименко и И.В. Липсиц всесторонне рассмотрели и описали этапы фрормирования ценовой стратегии на предприятии.

В представленных методиках имеется существенный недостаток, который заключается в том, что в них не включен и не предложен алгоритм проведения анализа ценовой политики предприятия с учетом всех элементов и меняющейся конъюнктуры рынка. Кроме того, недостаточно подробно рассмотрены проблемы адаптации ценовой политики к изменяющимся условиям внешней среды. Тем не менее нельзя сказать, что один метод анализа в рамках отдельного элемента лучше или хуже других, наоборот, их взаимодействие и взаимодополнение позволяют анализировать ценовую политику предприятия в полном объеме. Таким образом, на основе уже разработанных подходов, методик и принципов предложим свой вариант исследования. Так, анализ ценовой политики можно провести по следующим этапам (рис. 2):

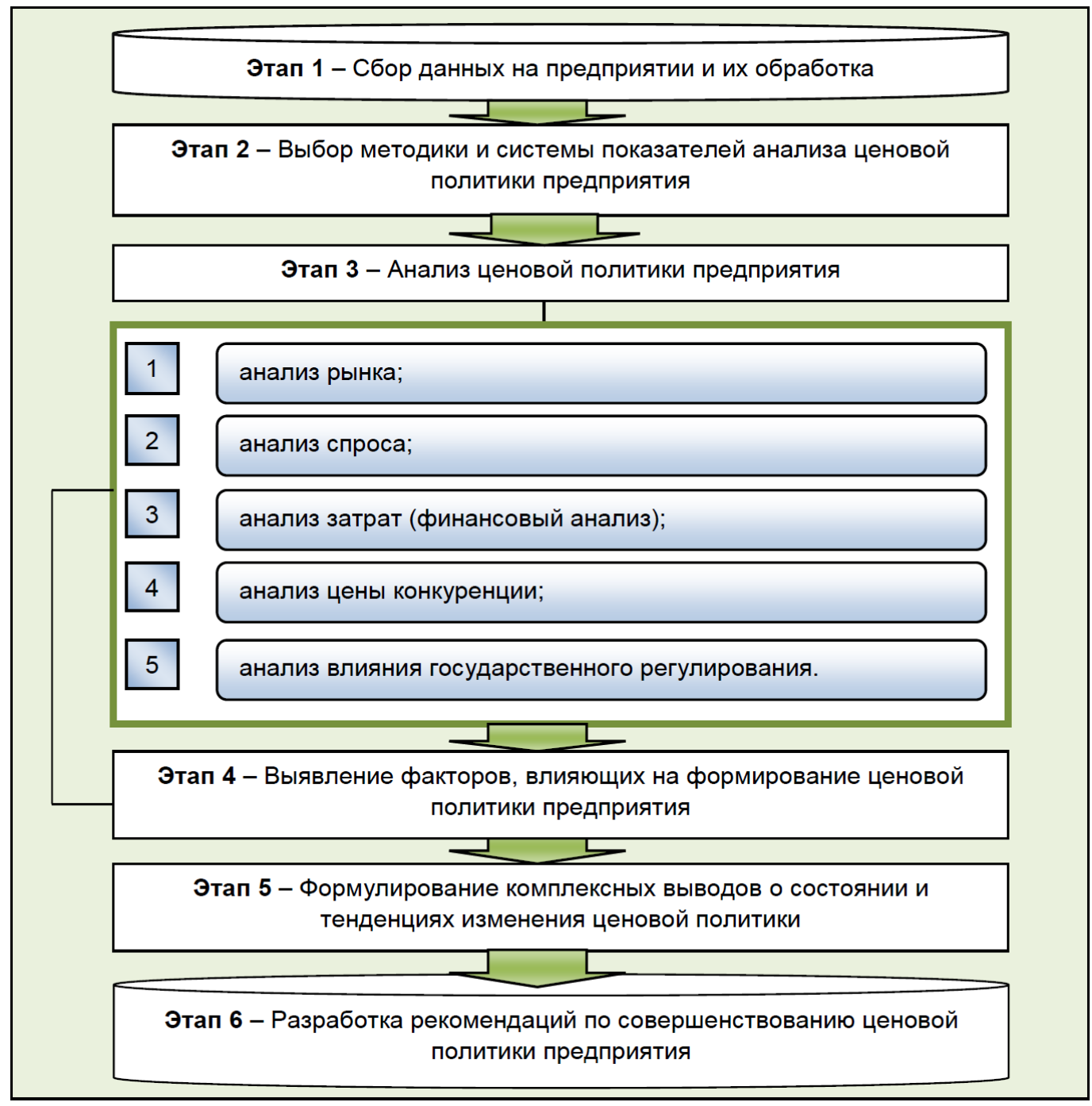

Рисунок 2 - Методика анализа ценовой политики предприятия

Целью данной методики является получение исчерпывающей информации о состоянии и эффективности ценовой политики на предприятии и о факторах, оказывающих наибольшее влияние на разработку и выбор ценовой политики, а также оперативный контроль и внедрение своевременных и необходимых изменений [7]. Необходимо отметить, что методика может быть адаптирована под конкретное предприятие, в нее могут быть внесены дополнительные операции и показатели.

Рассмотрим более подробно основные этапы и элементы анализа ценовой политики. Первым этапом работ является сбор исходной информации. Все источники данных для анализа хозяйственной деятельности предприятия принято подразделять на нормативно-плановые, учетные и внеучетные.

К источникам информации нормативно-планового характера относятся все типы планов, которые разрабатываются на предприятии (перспективные, текущие, оперативные, технологические карты), а также нормативные материалы, сметы, ценники, проектные задания и др. [8]. 
Источники информации учетного характера - это все данные, которые содержат документы бухгалтерского, статистического и оперативного учета, а также все виды отчетности, первичная учетная документация [9].

И, наконец, внеучетные источники информации - это документы, регулирующие хозяйственную деятельность, а также данные, характеризующие изменение внешней среды функционирования предприятия.

Второй этап предполагает выбор определенной методики анализа ценовой политики предприятия, то есть разработку программы и выбор системы показателей. В соответствии с этим принципы исследования заключаются в следующем:

- сопоставимость полученных данных с условиями внешней и внутренней среды;

- адаптированность и адекватность методики современным условиям функционирования предприятия;

- мобильность методики (возможность внесения изменений для адаптации к конкретному предприятию);

- обоснованность и объективность используемых показателей.

На третьем этапе проводится непосредственно сам анализ ценовой политики предприятия, основными мероприятиями которого являются следующие:

1. Анализ рынка.

2. Анализ спроса.

3. Анализ затрат (финансовый анализ).

4. Анализ цен и конкуренции.

5. Анализ влияния государственного регулирования.

В данном блоке обращается внимание на такие вопросы, как: оказывает ли государственная политика влияние на рынок и в чем оно выражается; какое воздействие оказывает государственная политика на отдельные фрирмы; оказывает ли государство фринансовую помощь фрирмам и др. [10].

В ходе проведения анализа выявляются факторы (причины), влияющие на изменение ценовой политики предприятия, причем факторы могут быть как положительного, так и отрицательного характера [11].

Завершающим этапом анализа является разработка рекомендаций по совершенствованию ценовой политики предприятия [12].

Таким образом, рассмотрев теоретические основы цены и ценовой политики предприятия, можно сделать вывод о том, что ценовая политика является одним из важнейших элементов механизма конкурентоспособности предприятия. Сущность ценовой политики предприятия состоит в том, чтобы устанавливать на товары (услуги) такие цены, так варьировать их в зависимости от ситуации на рынке, чтобы овладеть его максимально возможной долей, добиться запланированного объема прибыли и успешно решать все стратегические и тактические задачи. Для эфрективного функционирования предприятий необходимо проводить анализ их ценовой политики и на основе данного анализа вносить определенные изменения.

\section{Ссылки:}

1. Brucks M., Zeithaml V.A., Naylor G. Price and brand name as indicators of quality dimensions for consumer durables // Academy of Marketing Science. Journal. 2000. Vol. 28, no. 3. P. 359.

2. Strategic marketing patterns and performance implications / E. Agic, M. Cinjarevic, E. Kurtovic, M. Cicic // European Journal of Marketing. 2016. Vol. 50, no. 12. P. 2216-2248.

3. Кардаш М.А. Разработка политики ценообразования // Промышленный и b2b маркетинг. 2014. № 1. C. 45-54

4. Савицкая Г.В. Анализ хозяйственной деятельности сельскохозяйственных предприятий : конспект лекций. Минск, 2010.

5. Кеворков В.В. Какова роль подразделения маркетинга в разработке ценовой политики и плана продаж/производства? // Промышленный и b2b маркетинг. 2011. № 4. С. 11-17.

6. Данченок Л. Ценовая политика фирм // Человек и труд. 2012. № 12. С. 17-26.

7. Пострелова А.В. Оценка конкурентоспособности предприятия // Молодой ученый. 2013. № 6. С. 398-402.

8. Антонова Н.С. Ценовая политика как инструмент управления продажами в розничной торговле // Управление продажами. 2013. № 3. С. 67-72.

9. Архипова Д.В. Современные концепции механизма ценообразования // Молодой ученый. 2014. № 12. С. 131-133.

10. Зимина С.А. Роль анализа в формировании ценовой политики коммерческого предприятия // Международный научно-исследовательский журнал. 2014. № 11-3 (30). С. 27-28.

11. Гладких И.В. Политика справедливых цен как элемент маркетинговой стратегии компаний // Маркетинг и маркетинговые исследования. 2011. № 6. С. 26-32.

12. Коротков А.В. Установление цен на товары-новинки // Там же. 2012. № 3. С. 15-24. 


\section{References:}

Agic, E, Cinjarevic, M, Kurtovic, E \& Cicic, M 2016, 'Strategic marketing patterns and performance implications', European Journal of Marketing, vol. 50, no. 12, pp. 2216-2248. https://doi.org/10.1108/ejm-08-2015-0589.

Antonova, NS 2013, 'Price policy as a tool for managing sales in retail trade', Upravleniye prodazhami, no. 3, pp. 67-72, (in Russian).

Arkhipova, DV 2014, 'Modern concepts of the pricing mechanism', Molodoy uchenyy, no. 12, pp. 131-133, (in Russian).

Brucks, M, Zeithaml, VA \& Naylor, G 2000, 'Price and brand name as indicators of quality dimensions for consumer durables', Journal of the Academy of Marketing Science, vol. 28, no. 3, p. 359. https://doi.org/10.1177/0092070300283005.

Danchenok, L 2012, 'Price policy of companies', Chelovek i trud, no. 12, pp. 17-26, (in Russian)

Gladkikh, IV 2011, 'Fair value policy as an element of the company marketing strategy', Marketing i marketingovyye issledovaniya, no. 6, pp. 26-32, (in Russian).

Kardash, MA 2014, 'Pricing policy development', Promyshlennyy i b2b marketing, no. 1, pp. 45-54, (in Russian).

Kevorkov, VV 2011, 'What is the role of marketing in developing a pricing policy and a sales plan/an industrial scheme?', Promyshlennyy i b2b marketing, no. 4, pp. 11-17, (in Russian).

Korotkov, AV 2012, 'New-product pricing', Marketing i marketingovyye issledovaniya, no. 3, pp. 15-24, (in Russian).

Postrelova, AV 2013, 'Evaluation of company competitiveness', Molodoy uchenyy, no. 6, pp. 398-402, (in Russian).

Savitskaya, GV 2010, Analysis of agricultural company economic activities: lectures, Minsk, (in Russian).

Zimina, SA 2014, 'The role of analysis in pricing policy of a commercial company', Mezhdunarodnyy nauchno-issledovatel'skiy zhurnal, no. 11-3 (30), pp. 27-28, (in Russian). 